\title{
Toxicosis Gravídicas en el Instituto de Protección Materna e Infantil, durante los once últimos años
}

\author{
(Resumen de las comunicaciones presentadas a la Primera Con- \\ vención Nacional de Obstetricia y Ginecología, reunida en Bogotá).
}

INTRODUCCIÓN

Profesor Luis María Ferro

El Instituto de Protección Materna e Infantil, ha querido asociarse a la celebración de la Primera Convención Nacional de Obstetricia y Ginecología, y presenta un estudio estadístico basado en el examen de 64.297 historias clínicas correspondientes a enfermas hospitalizadas en el periodo comprendido entre los años de ¿942 a 1952 inclusive.

El Personal Científico del Instituto Profesores, Jefes de Clínica, e Internos, sin excepción alguna, emprendieron la ardua tarea de revisar y anotar, entre las citadas historias, las correspondientes a casos de toxicosis gravidicas.

El número total alcanzó la cifra de 1.174 casos, que representa una incidencia total de $1.082 \%$. Debo anotar que en el desarrollo de esta labor se tropezó con muchas dificultades: la primera y más grande de las cuales fue la forma defectuosa con que habian sido llevadas las historias clínicas, falla y defecto de que todos somos culpables. Creo que el convencimiento de nuestros errores y su pronta corrección $\mathrm{y}$ el esmero y cuidado puesto en lo sucesivo en el desarrollo de las historias clínicas, sean, el primero y más útil de los resultados de este trabajo y de esta Convención.

Fallamos también en la debida conexión de la clínica con el laboratorio y en el intercambio de ideas y estudios con otros centros hospitalarios.

Las toxicosis gravidicas constituyen el más serio capitulo de la patología obsiétrica. Su tremenda gravedad, la rapidez de su evolución, la morbilidad y la mortalidad elevadísimas, justifican toda una lucha tenaz para su profilaxis y precoz diagnóstico.

Es nuestra opinión sincera apoyada en la propia experiencia, que la vigilancia estricta del embarazo en las consultas prenatales es la mejor arma que poseemos para combatir tan terribles complicaciones, que son, hoy por hoy, las que dentro de la mortalidad total de los hospitales y clínicas de maternidad alcanzan una cifra más elevada.

La incidencia que hemos encontrado es relativamente baja con respecto a otros centros similares, pero ésto lo atribuyo a defecto en las historias clínicas, a falta de sistemáticos exámenes de laboratorio, y a defectuosas conexiones con las demás consultas prenatales que funcionan en la ciudad. 